DOI: https://doi.org/10.25146/2587-7844-2021-13-1-66

\title{
УДК 81-114.2
}

\section{ОРФОГРАФИЧЕСКАЯ НОРМА КАК САКРАЛЬНЫЙ ФЕНОМЕН}

\section{А.Д. Васильев (Красноярск, Россия)}

\section{Аннотация}

Постановка проблемы. Норма является чрезвычайно важной категорией, служащей для упорядочения разнообразной деятельности общества. С помощью представлений о норме формируется аксиологическая шкала, которая, в зависимости от фундаментальных обстоятельств, подвержена ремаркированию: сакральное и профанное меняются местами.

Это относится и к вопросам языковой политики, наиболее наглядно обнаруживаясь в области правописания. Именно в установлении единых правил орфографии и пунктуации государство проявляет свою волю самым зримым образом.

Цель - социолингвистический анализ орфографических реформ и их результатов.

Методология. Социолингвистический анализ предполагает анализ языковых явлений на основе заявленной концепции в конкретных исторических и общественных условиях, а также с учетом социальных, психологических, языковых особенностей аудитории, на которую они ориентированы.

Результаты исследования. Истории русского языка знакомы случаи радикального орфографического реформирования. Однако самый известный из них (1917 г.), когда правописание было решительно упрощено для скорейшего овладения им широкими массами, повлек весьма негативные психосоциальные последствия - резко пренебрежительное отношение к практическому соблюдению правил.

Самый свежий пример проекта реформы русской орфографии в XXI в. был воплощен в 2007 г., но не получил официального утверждения.

Bblводы и заключение. Исходя из сакрального статуса русского языка как одного из ключевых символов государства, следует жестко упорядочить соблюдение имеющихся правил русской письменной речи. Целесообразно также регулярное издание постоянно дополняемых орфографических словарей - при их обязательном официальном утверждении.

Ключевые слова: русский язык, орфографические и пунктуационные правила, реформы правописания, психосоциальные и социокультурные последствия реформ, орфографические установки как сакральные изенности.

остановка проблемы. Норма вообще выступает необходимейшей понятийной категорией, служащей разумному упорядочению многообразной человеческой деятельности. Нормы могут быть облечены в соответствующие установления и основываться на различных (иногда - сходных) по природе фундаментах: обычаях и традициях, мифологии и религии, идеологии и законотворчестве. Нормы нередко подвергаются трансформациям; иногда - частичным, иногда - всеобъемлющим. В основном это происходит при смене доминирующей конфессии и / или социально-экономического устройства, когда радикально 
ремаркируется аксиологическая школа («что такое хорошо и что такое плохо»). Иначе говоря, прежнее сакральное объявляется профанным - и наоборот.

Строгая регламентация поведения людей, межличностных отношений на разных уровнях, от внутрисемейных до международных, от застольного этикета до государственных мероприятий включительно, несомненно играет преимущественно положительную роль.

Однако иногда чрезмерно жесткое регулирование жизни социума, например, в виде всеобщего нивелирования (а не равенства) и подавления любых инициатив, способно обеспечить самые негативные результаты как для отдельной личности, так и для макроколлективов (хрестоматийные иллюстрации см., например, в [Салтыков-Щедрин, 1953, с. 159; Замятин, 1989, с. 518-521; Набоков, 1990, с. 256 ; и др.]).

Впрочем, с течением времени способы моделирования поведения людей становятся все более изощренными и даже латентными, далеко не всегда будучи подаваемыми через четкую кодификацию в виде обнародуемых законов и проч., но внедряясь в общественное сознание по каналам СМИ (в телесериалах, «токшоу», выпусках новостей и даже в рекламных сюжетах).

Революционные изменения аксиологической парадигмы решительно перемещают координаты сознания и мироощущения социума - в интересах инициаторов и конструкторов «времени перемен» (см. об этом [Кара-Мурза, 2002, с. 546-552; и др.]). В результате - вероятно, пока еще промежуточном - «в России произошла странная трансформация самого понятия «нормальное», «норма» [Прилепин, 2008, с. 197] (также [Кара-Мурза, 2002, с. 556]). Ср. о свершившемся вступлении РФ в фазу политкорректности: «В рамках общества меньшинств <.. > [политкорректные ценности] стали обретать статус абсолютной идеологической нормы, оказываясь при этом противопоставленными < ..> ценностям большинства» [Ионин, 2012, с. 107] (см. также [Васильев, 2013, с. 231-295]). В целом же происходящие в стране процессы убедительно подтверждают, что «философия социал-дарвинизма <..> актуальна как никогда. <...>. Она и есть - наша государственная идеология» [Прилепин, 2009, с. 34]1․

Обзор литературьл. Применительно к языку норму считают одним из центральных лингвистических понятий [Крысин, 2006, с. 295], причем следует уточнить, что это относится преимущественно к литературному языку, нормы которого четко кодифицированы. Разумеется, норма устанавливается действующей властью - по крайней мере, с ее официального благоволения.

Следует, однако, напомнить, что вопрос, которым небезосновательно задавался Н.Г. Комлев - «о роли классов или социальных слоев в формировании речевых

\footnotetext{
${ }^{1}$ Недавно главный краевой полицейский, комментируя по местному телеканалу штурм подпольной студии, где в порносюжетах снимались несовершеннолетние девочки, заявил, что действия шоу-бизнесменов грубо нарушают «мораль». Однако непонятно, какая именно «мораль» существует в т.н. «рыночной экономике»: ведь упомянутое предприятие наверняка было рентабельным, следовательно - вполне уместным.
} 
эталонов. Является ли господствующий класс также господствующим в отношении языка?» [Комлев, 2003, с. 121], сам цитируемый автор считал нерешенным [Там же].

Действительно, ряд исторических примеров свидетельствует о безуспешности волюнтаристских попыток российских самодержцев подчинить своей единоличной воле стихию языка. Так, Павел I в 1797 г. высочайше повелел вывести из публичного оборота - руководствуясь заботой об идеологическом целомудрии подданных - слова́ отечество, гражданин, общество и другие, что, впрочем, никак не сказалось на их судьбе [Веселитский, 1972, с. 174, 192-193].

С другой стороны, есть, по крайней мере, одна область языкового строительства, которая, в силу своей зримой стандартизованности, оказывается легко достижимой для властного регулирования; она же является предметом непреходящего интереса и для значительной части общества. Это - орфография, то есть, по хрестоматийной дефиниции, - «система правил, устанавливающая единообразные способы передачи речи на письме» [Ахманова, 1966, с. 294]. Иногда, при засилье бюрократии, неверное оформление требуемого документа становится формальной причиной в отказе на юридически обоснованное прошение т.н. «рядового носителя языка» [Голев, 2008, с. 5 и др. $]^{2}$.

Цель - социолингвистический анализ орфографических реформ и их результатов.

Методология. Социолингвистический анализ предполагает анализ языковых явлений на основе заявленной концепции в конкретных исторических и общественных условиях, а также с учетом социальных, психологических, языковых особенностей аудитории, на которую они ориентированы, с целью установить причинные связи текста между языком и фактами общественной жизни. В данном случае концептуально автор опирается на дефиницию нормы в языкознании: «НОРMA англ. norm. 1. Принятое речевое употребление языковых средств, совокупность правил (регламентации), упорядочивающих употребление языковых средств в речи индивида. Норма орфоэпическая (норма произносительная). Норма речевая. Норма стилистическая. Норма грамматическая англ. grammar norm, statement of usage. Совокупность грамматических правил, выводимых из языковой практики, имеющая целью направлять и упорядочивать речевую деятельность говорящих на данном языке, а Русск. хочу - хотят, а не хочут. Норма лексическая англ. lexical norm. Норма словоупотребления, принятая в данном языке. Норма литературная англ. literary norm. Норма, определяющая образцовое применение (употребление) языковых средств. Нормы кодификация см. кодификация нормы»³.

\footnotetext{
2 Такая квалификация статуса граждан представляется довольно дискуссионной: хотя из дальнейшего текста становится понятным, что имеются в виду нелингвисты [Голев, 2008, с. 16], но цитируемый автор дифференцирует их на собственно «рядовых (в социальном смысле)»и «высокопоставленных» [Голев, 2008, с. 14]. С сугубо научной точки зрения у некоторых индивидуумов из числа последних лишь больше административных возможностей в поле языковой политики, но по сути - они такие же «рядовые», как и прочие (и лингвисты тоже).

${ }^{3}$ Ахманова О.С. Словарь лингвистических терминов. М., 1966. URL: https://classes.ru/grammar/174.Akhmanova/source/worddocuments/_51.htm
} 
Результаты исследования. Отметим, что в былые времена умение применять в письменной практике знание орфографии имело чрезвычайную значимость и могло повлиять на социальные перспективы адресанта. Например, будущий великий русский историк В.О. Ключевский сообщал в частном письме, что филолог Ф.И. Буслаев напутствовал его в числе абитуриентов Московского императорского университета перед началом работы над вступительным сочинением словами: «...Обратите особенное внимание на правописание: одна орфографическая ошибка отнимает право на поступление в университет»; Ключевский получил «очаровательную „,5”» [Ключевский, 1990, т. IX, с. 133-134]. Конечно, престиж владения правописанием особенно рельефно выступал на фоне неграмотности большинства подданных империи.

Такое положение дел было решительно устранено советской властью, которая исторически беспрецедентно озаботилась обучением грамоте широких народных масс и провела кампанию ликбеза (см. [Васильев, 2018, с. 43-44]).

Ей предшествовала орфографическая реформа, подготовленная задолго до революционных событий, но без колебаний и проволо́чек незамедлительно осуществленная именно большевиками (подробнее [Григорьева, 2004, с. 124; и далее]). Понятно, что они заботились почти равным образом и о распространении научно-технических знаний, и о максимальной доступности своей пропаганды и агитации.

Во вступительной части «Декрета Наркомпроса ${ }^{4}$ о введении нового правописания от 23 декабря 1917 г.» сообщалось, что это масштабное мероприятие производится «в целях облегчения широким народным массам усвоения русской грамоты, поднятия общего образования и освобождения школы от ненужной и непроизводительной траты времени и труда при изучении правил правописания» (цит. по: [Григорьева, 2004, с. 293]). Из этой формулировки явствует, что намерения власти были несомненно благими.

Но, как показывает исторический опыт - и вовсе не только отечественный, благие намерения нередко увенчиваются не самыми желательными результатами.

Конечно, в самом общем виде итоги ликбеза следует признать положительными. Но обнаружился также и психосоциальный эффект, в значительной степени предсказуемый, однако, как обычно и происходит (по сей день включительно), то ли не учтенный творцами реформы, то ли сочтенный ими ничтожно малым.

Между тем почти синхронно с распространением грамотности возникло и массовое нигилистическое отношение к соблюдению каких бы то ни было орфографических правил. На этот негативный резонанс обратил внимание проницательный Л.В. Щерба: «Может показаться странным, что после проведения реформы орфографии, которая и была задумана в значительной мере в целях облегчения достижения полной грамотности, результаты получились как раз обратные ожидаемым <..>. Реформа не сделала орфографию безусловно легкой, но зато в корне подорвала ее престиж» [Щерба, 1957, с. 56]. Иначе говоря, соблюде-

\footnotetext{
${ }^{4}$ Народного комиссариата просвещения.
} 
ние идеологически верного «плана содержания» явочным порядком преобладало над стремлением к правильному оформлению «плана выражения» (термины Л.В. Щербы), в том числе и с позиций орфографии. «Практический вывод, который был сделан отсюда < ..> почти всем обществом, был тот, что орфография вещь неважная, пиши, дескать, как хочешь, не в том сила <...>. Эта новая оценка орфографии была подкреплена свойственным всем революционным эпохам презрением к „форме” и погоней за „существом” [Щерба, 1957, с. 57].

Сто́ит отметить, что положения о причинах безграмотности, сформулированные Л.В. Щербой, актуальны и по сей день: отсутствие внутренней дисциплины у многих школьников (а теперь - и у людей постарше, чья молодость была осенена странноватым перестроечным лозунгом «Разрешено все, что не запрещено!»; автору случалось дискутировать с сотрудницами учебного отдела юридического вуза, искренне не понимавшими, зачем нужно писать грамотно); «усердие не по разуму», проявляемое администраторами от образования, требующими насаждать новые методы (теперь - инновационные методики и цифровизацию ради инноваций и цифровизации, точнее - грядущей элиминации из учебного процесса фигуры учителя как такового) 5 ; малая начитанность школьников [Щерба, 1957, с. 62-63].

Советские учителя и руководители системы образования настойчиво и неоднократно пытались переломить пренебрежительное отношение школьников к овладению русской орфографией, используя различные формы и способы.

Так, в 1954 г. был введен «Единый школьный режим грамотного письма и культуры речи» - «строго очерченный круг требований к общей грамотности и культуре устной и письменной речи учащихся, выполнения которых должны добиваться все учителя школы» (цит. по: [Текучев, 1982, с. 105]), то есть независимо от того, какие предметы они преподают.

Однако эти и им подобные попытки в общем-то разумного орфографического режима закончились паллиативом. Академик А.В. Текучев предложил создать «так называемый орфографический и пунктуационный минимум (по отношению ко всем мыслимым и существующим написаниям) и он же - максимум (поскольку большего от школы и ученика требовать нельзя)» [Текучев, 1982, с. 13]. Небезынтересно, что в результате таких экзерсисов предполагалась четкая функцио-нальная дифференциация прикладной орфографии: в официальной корреспонденции - обязательность соблюдения правил, в лично-бытовой переписке - ослабление тех же требований [Там же].

Кроме того, почти постоянно проектировались новые своды правил. Типологически они во многом были взаимоподобны, поскольку следовали по пути «фонетизации орфографии», то есть максимального приближения написания к произношению (подробнее см. [Григорьева, 2004, с. 207-228; и др.]).

\footnotetext{
5 Например, в красноярской «сфере образовательных услуг» поощряется обучать младшеклассников не началам понимания и осмысления художественного текста, а лишь передавать его содержание картинками определенных цветов (2020 г.).
} 
Прежде чем коснуться последнего по счету грандиозного послесоветского орфографического проекта, следует упомянуть о ряде Федеральных целевых программ «Русский язык», кажется, также затевавшихся с благими намерениями, начиная с 1996 г. - под флагом «духовного обновления и возрождения России» (см. [Васильев, 2008, с. 117-159]). Насколько полно были реализованы программы, широкая общественность так и не узнала. Но в них упоминалось о «необходимости создания норм русского литературного языка» - очевидно, речь шла о новейшей орфографической реформе.

Действительно, почти одновременно с этими программами стали появляться публикации, предварявшие воплощение преобразовательских замыслов. Сто́ит отметить, во-первых, что их инициаторы и популяризаторы декларировали как свою главную цель «не изменения в правилах, а сам факт [!] официального утверждения нового, полного, современного свода правил» [Лопатин, 2001, с. 60]. Во-вторых, применялся словесный камуфляж - вроде: «то, что подготовлено нами, - это отнюдь не реформа» [Лопатин, 2001, с. 55] (вероятно, с учетом настороженного отношения к слову реформа, выработанного у многих «уважаемых россиян» опытом собственного выживания). В-третьих, по-настоящему публичного обсуждения «нереформы» специалистами не производилось (как, собственно, случается со всеми преобразовательскими изобретениями в постсоветской России) [Васильев, 2008, с. 54-56]. Наконец, остались неизвестными и экономические расчеты по поводу финансовых затрат на внедрение правописных новшеств.

В результате были изданы «Правила русской орфографии и пунктуации. Полный академический справочник» (М., 2007. 480 с.) под грифом Российской академии наук. Впрочем, на титульном листе этого издания значится буквально: «Одобрено Орфографической комиссией РАН», а председателем ее в тот момент являлся В.В. Лопатин [Правила, 2007..., с. 9], по существу, следовательно, одобривший реализацию собственного замысла и выступивший в качестве ответственного редактора данной книги (см. [Правила..., 2007, с. 2]).

Справедливо замечено, что названный опус не имеет государственного утверждения, а «между утвержден и одобрен есть некоторое различие» [Григорьева, 2011, с. 27] (об этом важном обстоятельстве упомянул и Н.М. Кропачев в ходе известного мероприятия, кстати, определив итог трудов орфографовнереформаторов как «неудачную попытку» [Заседание Совета, 2019]).

Кажется, на какое-то время революционный пыл активистов от правописания поутих.

Однако это не означает прекращения процессов, которые происходят при употреблении конкретного живого языка. Многие его феномены нуждаются в упорядочении при использовании в письменной речи. Например, регламентация прописных букв, особенно в составных именованиях и их аббревиатурах; стандартизованная кириллическая передача ряда иноязычных заимствований; четкая фиксация инвариантных написаний имен собственных и др. В таком направлении и необходимы усилия специалистов. 
Глубоко справедливо суждение В.В. Путина: «...Совершенствование и правового поля, и самих норм русского языка не должно означать каких-то „революционных" изменений и уж тем более вульгарного упрощенчества в орфографии и пунктуации» ${ }^{6}$.

Следовательно, для решения ряда насущных задач в области русского правописания нет необходимости в радикальном реформаторстве. Для обеспечения практических потребностей пишущих вполне достаточно подтверждения имеющихся принципов и правил орфографии и пунктуации с очень осторожным, взвешенным и продуманным введением частных комментариев и примечаний. Такие дополнения к правописным нормам (а вовсе не узусу) следует отражать в регулярно (ежегодно) переиздаваемых - при условии их официального санкционирования - общедоступных словарях.

Впрочем, представляется актуальной еще одна задача, имеющая не только культурно-образовательный характер. Это возвращение - конечно, в разумных пределах, - к орфографическому режиму. «Орфографический плюрализм» [Григорьева, 2004, с. 229], несомненно, привлекателен для многих по ряду причин, и не в последнюю очередь - из-за предоставляемой им возможности не напрягаться интеллектуально, то есть обрести некое подобие свободы - по сути, ее имитации. Закрепить обязательность соблюдения правописных норм - безусловно, приоритет государства. Именно русский, согласно ст. 68 Конституции ${ }^{7}$, является государственным языком РФ (любопытно, что остальные государственные символы - флаг, герб и гимн - перечислены ниже, в ст. 70). Значит, в силу своего статуса он является сакральной ценностью, профанизировать которую кощунственно, в том числе и в форме ошибок на письме ${ }^{8}$ Хотя и не прекращается явно надуманное в чьих-то интересах и интенсивное смысловое разграничение понятий «русский язык» и «государственный язык», доводимое чуть ли не до противопоставления денотатов (об этом следует говорить особо), повсеместное следование орфографическим постулатам не подлежит обсуждению - как выполнение санитарно-гигиенических рекомендаций при пандемии.

Bblводы и заключение. Исходя из сакрального статуса русского языка как одного из ключевых символов государства, следует жестко упорядочить соблюдение имеющихся правил русской письменной речи. Целесообразно также регулярное издание постоянно дополняемых орфографических словарей - при их обязательном официальном утверждении.

${ }^{6}$ Путин В.В. Заседание Совета. 2019.

${ }^{7}$ Конституция. 2009. С. 4.

${ }^{8}$ Во всех жанрово-тематических текстах, предназначенных для публичного оборота, например рекламных. Судя по оформлению последних, редакторам СМИ ничего не известно о правилах русской пунктуации (иногда - и орфографии). Допустим, что это - область компетенции маркетологов. Любопытно, однако, было бы узнать, насколько эффективны такие приемы, и не только в коммерческом отношении, но и для пропаганды тлетворного права на безграмотность. 


\section{Библиографический список}

1. Ахманова О.С. Словарь лингвистических терминов. М., 1966. 608 с. URL:https://classes. ru/grammar/174.Akhmanova/source/worddocuments/_51.html (дата обращения: 20.01.2021).

2. Васильев А.Д. Игры в слова. Манипулятивные операции в текстах СМИ. СПб., 2013. 660 с.

3. Васильев А.Д. Письменность, алфавиты, орфография: история и современность. Красноярск, 2018. 164 с.

4. Васильев А.Д. Российская языковая политика 1991-2005 гг. Красноярск, 2008. 176 с.

5. Веселитский В.В. Отвлеченная лексика в русском литературном языке XVIII - начала XIX в. М., 1972. 320 c.

6. Голев Н.Д. Особенности современного обыденного метаязыкового сознания в зеркале обсуждения вопросов языкового строительства // Вестник Томского государственного университета. Филология. 2008. № 3 (4). С. 5-17.

7. Григорьева Т.М. «Орфографическая распря» в истории русского языка // Язык и социальная действительность. Красноярск, 2011. № 1. С. 19-28.

8. Григорьева Т.М. Три века русской орфографии (XVIII-XX вв.). М., 2004. 456 с.

9. Замятин Е.И. Последняя сказка про Фиту // Замятин Е.И. Избранные произведения. М., 1989. С. 518-521.

10. Заседание Совета по русскому языку 5 ноября 2019 г. URL: http://www.kremlin.ru/events/ president/news/61986 (дата обращения: 20.01.2021).

11. Ионин Л. Политкорректность: дивный новый мир. М., 2012. 112 с.

12. Кара-Мурза С.Г. Манипуляция сознанием. М., 2002. 832 с.

13. Ключевский В.О. Письмо П.П. Гвоздеву // Ключевский В.О. Собр. соч.: в 9 т. М., 1990. T. IX. C. 129-138.

14. Комлев Н.Г. Слово в речи. Денотативные аспекты. Изд. 2-е. М., 2003. 216 с.

15. Конституция Российской Федерации // Российская газета. 2009. № 7 (4831). 21 января. С. 3-5.

16. Крысин Л.П. Языковая норма в проекции на современную речевую практику // Русский язык сегодня. М., 2006. Вып. 4: Проблемы языковой нормы. С. 294-311.

17. Лопатин В.В. О новом своде правил русского правописания // Русский язык в школе. 2001. № 2. C. 55-60.

18. Набоков В.В. Подвиг // Набоков В.В. Собр. соч.: в 4 т. М., 1990. Т. 2. С. 155-296.

19. Правила русской орфографии и пунктуации. Полный академический справочник. М., 2007. $480 \mathrm{c}$.

20. Прилепин 3. Действительно не понимаю // Прилепин 3. Terra Tartarara: Это касается лично меня. М., 2009. С. 29-37.

21. Прилепин 3. К нам едет Пересвет // Прилепин 3. Я пришел из России. СПб., 2008. С. 196-199.

22. Салтыков-Щедрин М.Е. История одного города. М., 1953. 198 с.

23. Текучев А.В. Об орфографическом и пунктуационном минимуме в средней школе. М., $1982.111 \mathrm{c}$.

24. Щерба Л.В. Безграмотность и ее причины // Щерба Л.В. Избранные работы по русскому языку. М., 1957. С. 56-62.

\section{Сведения об авторе}

Васильев Александр Дмитриевич - доктор филологических наук, профессор кафедры общего языкознания, Красноярский государственный педагогический университет им. В.П. Астафьева; e-mail: vasileva@kspu.ru 


\section{DOI: https://doi.org/10.25146/2587-7844-2021-13-1-66}

\section{SPELLING NORM AS SACRED PHENOMENON}

\section{A.D. Vasilyev (Krasnoyarsk, Russia)}

\section{Abstract}

Statement of the problem. The norm is an extremely important category that serves to regulate the diverse activities of society. With the help of ideas about the norm, an axiological scale is formed. Depending on the fundamental circumstances this scale is subject to remarking: the sacred and the profane change places.

This also applies to issues of language policy, most clearly found in the field of spelling. It is in establishing uniform rules of spelling and punctuation that the state manifests its will in the most visible way.

The purpose of the article is sociolinguistic analysis of spelling reforms and their results.

Research methodology. Sociolinguistic analysis involves the analysis of language phenomena on the basis of the stated concept in specific historical and social conditions, as well as taking into account social, psychological, and linguistic characteristics of the audience to which they are aimed.

The results of the study. The history of the Russian language knows cases of radical spelling reforms. However, the most famous of them (1917), when spelling was drastically simplified to facilitate its mastering by people at large, entailed very negative psychosocial ramifications, in effect, a sharply contemptuous disregard of rules.

The most recent example of the project for the Russian spelling reform in the $21^{\text {st }}$ century was developed in 2007, but did not receive official approval.

Conclusions. Russian should be strictly regulated in accordance with the existing rules of the Russian written language, based on the sacred status of the Russian language as one of the key symbols of the state. It is also advisable to regularly publish constantly updated spelling dictionaries after their mandatory official approval.

Keywords: Russian language, spelling and punctuation rules, spelling reforms, psychosocial and sociocultural ramifications of reforms, spelling settings as sacred values.

\section{References}

1. Akhmanova O.S. Dictionary of linguistic terms. M., 1966. 608 p. URL: https://classes.ru/grammar/174.Akhmanova/source/worddocuments/_51.html (accessed: 20.01.2021).

2. Vasil'ev A.D. Word games. Manipulative operations in media texts. St. Petersburg, 2013. 660 p.

3. Vasiliev A.D. Writing, alphabets, orthography: history and modernity. Krasnoyarsk, 2018. 164 p.

4. Vasilev A.D. the Russian language policy 1991-2005. Krasnoyarsk, 2008. 176 p.

5. Veselitskiy V.V. Abstract vocabulary in the Russian literary language of the XVIII - early XIX centuries. M., 1972. 320 p.

6. Golev N.D. Features of modern everyday metalanguage consciousness in the mirror of discussion of issues of language construction // Bulletin of Tomsk State University. Philology. 2008. No. 3 (4). P. 5-17.

7. Grigorieva T.M. "Orthographic strife" in the history of the Russian language // Language and social reality. Krasnoyarsk, 2011. No. 1. P. 19-28.

8. Grigorieva T.M. Three centuries of Russian orthography (XVIII-XX centuries.). M., 2004. $456 \mathrm{p}$.

9. Zamyatin E.I. the Last tale about the fit // Zamyatin E. I. Selected works. M., 1989. P. 518-521. 
10. Meeting of the Russian Language Council on November 5, 2019. URL: http://www.kremlin.ru/ events/president/news/61986 (accessed: 20.01.2021).

11. Ionin L. Political correctness: brave new world. M., 2012. 112 p.

12. Kara-Murza S.G. Manipulation of consciousness. M., 2002. 832 p.

13. Klyuchevsky V.O. Letter to P.P. Gvozdev // Klyuchevsky V.O. Col. works: in 9 vol. M., 1990. Vol. IX. P. 129-138.

14. Komlev N.G. Word in speech. Denotative aspects. Ed. 2. M., 2003. 216 p.

15. The Constitution of the Russian Federation // Rossiyskaya gazeta. 2009. No. 7 (4831). January 21. P. 3-5.

16. Krysin L.P. Linguistic norm in projection on modern speech practice. Russian language today. Problems of the language norm. M., 2006. Is. 4. P. 294-311.

17. Lopatin V.V. Russian Russian Language at School: About the new set of rules of Russian spelling. 2001. No. 2. P. 55-60.

18. Nabokov V.V. Podvig // Nabokov V.V. Col. works: in 4 vol. 1990. Vol. 2. P. 155-296.

19. Rules of Russian spelling and punctuation. Complete academic reference book. M., 2007. 480 p.

20. Prilepin Z. I really don't understand // Prilepin Z. Terra Tartarara: This concerns me personally. M., 2009. P. 29-37.

21. Prilepin Z. To us goes Peresvet // Prilepin Z. I came from Russia. St. Petersburg, 2008. P. 196-199.

22. Saltykov-Shchedrin M.E. History of a city. M., 1953. 198 p.

23. Tekuchev A.V. On the orthographic and punctuation minimum in secondary school. M., 1982. $111 \mathrm{p}$.

24. Shcherba L.V. Illiteracy and its causes // Shcherba L.V. Selected works on the Russian language. M., 1957. P. 56-62.

\section{About the author}

Vasilyev Alexander Dmitrievich - Doctor of Philology, Professor of the Department of General Linguistics, Krasnoyarsk State Pedagogical University named after V.P. Astafyev; e-mail: vasileva@kspu.ru 